This item was submitted to Loughborough's Research Repository by the author.

Items in Figshare are protected by copyright, with all rights reserved, unless otherwise indicated.

\title{
Regional microclimate humidity of clothing during light work as a result of the interaction between local sweat production and ventilation
}

PLEASE CITE THE PUBLISHED VERSION

http://dx.doi.org/10.1108/09556220610668473

\section{PUBLISHER}

(C) Emerald

VERSION

AM (Accepted Manuscript)

\section{LICENCE}

CC BY-NC-ND 4.0

\section{REPOSITORY RECORD}

Ueda, Hiroyuki, Yoshimitsu Inoue, Mitsuo Matsudaira, Tsutomu Araki, and George Havenith. 2019. "Regional Microclimate Humidity of Clothing During Light Work as a Result of the Interaction Between Local Sweat Production and Ventilation". figshare. https://hdl.handle.net/2134/12496. 
This item was submitted to Loughborough's Institutional Repository (https://dspace.lboro.ac.uk/) by the author and is made available under the following Creative Commons Licence conditions.

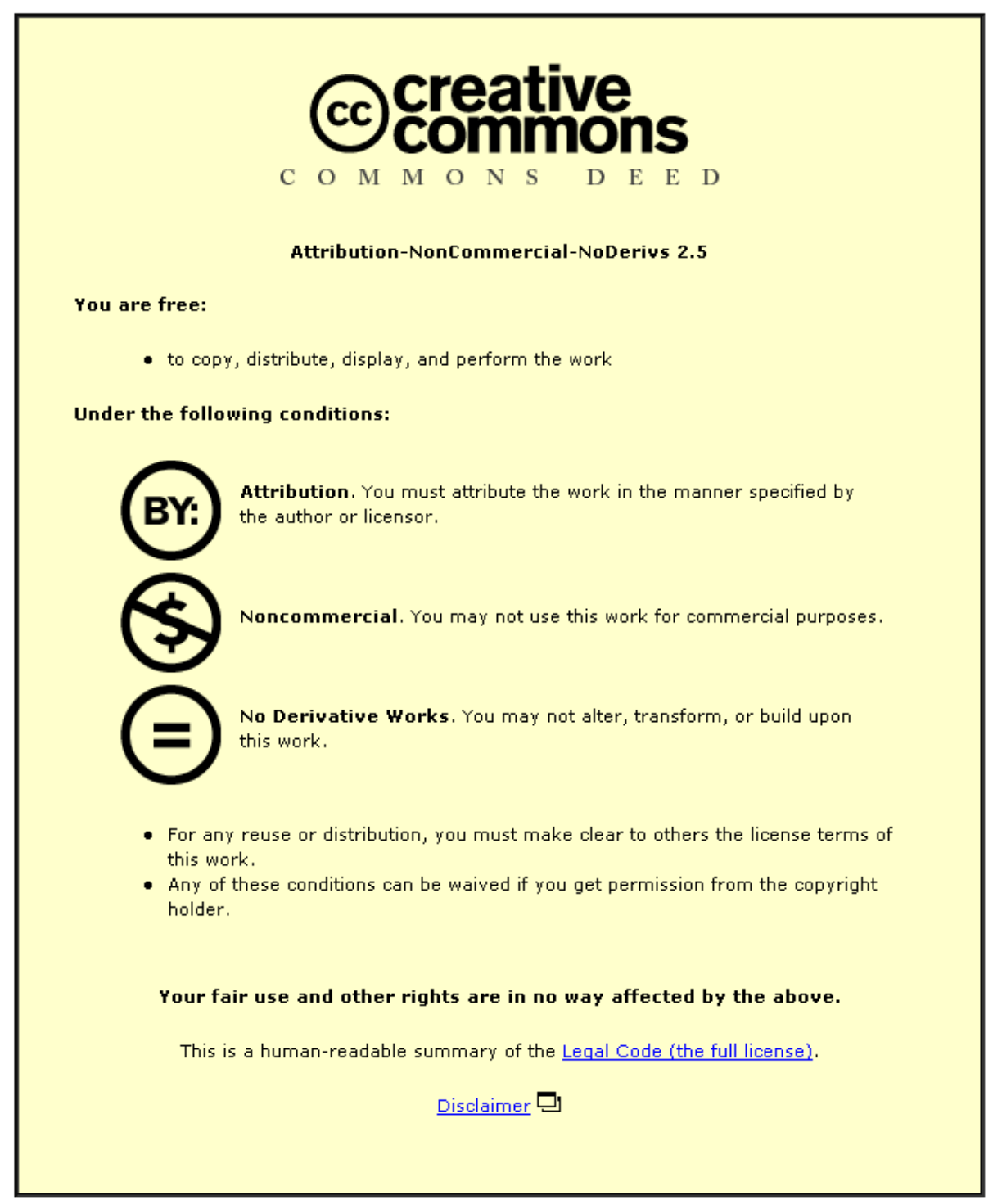

For the full text of this licence, please go to: http://creativecommons.org/licenses/by-nc-nd/2.5/ 


\title{
Regional Microclimate Humidity of Clothing during Light Work as a Result of the Interaction between Local Sweat Production and Ventilation
}

\author{
Hiroyuki Ueda \\ Osaka Shin-Ai College \\ 6-2-28 Tsurumi, Tsurumi-ku, Osaka 538-0053, Japan \\ Tel:+81-6-6180-1041 Fax:+81-6-6180-1045 \\ E-mail:ueda@osaka-shinai.ac.jp \\ Yoshimitsu Inoue \\ Osaka International University, Japan \\ Mitsuo Matsudaira \\ Kanazawa University, Japan \\ Tsutomu Araki \\ Hyogo University of Teacher Education, Japan \\ George Havenith
}

Dept. Human Sciences, Loughborough University, UK 


\begin{abstract}
Purpose - The aim of this study was to explore the influence of the clothing ventilation in three body regions on the humidity of the local clothing microclimates under five work-shirts immediately after the onset of sweating in light exercise.
\end{abstract}

Methodology/approach - The clothing microclimate ventilations were measured at chest, back and upper arm using a manikin. Separate wear trials were performed to determine the sweat production and the humidity of the clothing microclimate at the same locations as where the ventilation was measured during light exercise.

Findings - Every shirt shows the greatest value of Ventilation Index for the chest and the smallest one for the upper arm. The values of Ventilation Index differ remarkably at the chest among the five shirts. Comfort sensation became gradually worse as the time passed after starting exercise and a difference in sensation votes among the clothing conditions was observed after the onset of sweating. There was no significant difference among the clothing conditions in mean values of rectal temperature, local skin temperatures, microclimate temperatures, microclimate relative humidities and local sweat rates at three regions over 10 min after the onset of sweating. However, a clear relationship was observed between the ratio of the mean moisture concentration in the clothing microclimate to the mean sweat rate at the chest and the back and the Ventilation Index.

Originality/value - Moisture concentration in the clothing microclimate was contrasted with clothing ventilation at different body regions. This result suggests that in order to evaluate the conformability of wears, clothing ventilation should be measured in different body regions in response to sweat rates in corresponding regions.

Keywords : microclimate humidity, clothing ventilation, sweat rate, regional difference, thermal comfort

Article type: Research paper 


\section{Nomenclature}

$A$ : atmospheric oxygen concentration $(20.9 \%)$

$B(0)$ : constant value giving the difference between $A-O(t)$ at $t=0(\%)$

$H R$ : heart rate (bts $\left.\min ^{-1}\right)$

msw : local sweat rate

$\mathrm{O}_{2}(t)$ : oxygen concentration at time $\mathrm{t}(\%)$

$R$ : air resistance of fabric $\left(\mathrm{kPa} \mathrm{sec} \mathrm{m}^{-1}\right)$

Rae : air exchange rate $\left(\mathrm{min}^{-1}\right)$

$R H m$ : relative humidity of clothing microclimate $(\%)$

$\mathrm{Tm}$ : temperature of clothing microclimate $\left({ }^{\circ} \mathrm{C}\right)$

Tsk : local skin temperature $\left({ }^{\circ} \mathrm{C}\right)$

Tre : rectal temperature $\left({ }^{\circ} \mathrm{C}\right)$

$V$ : fixed flow rate for measuring air resistance of fabric $\left(0.04 \mathrm{~m}^{3} \mathrm{~m}^{-2} \mathrm{sec}^{-1}\right)$

$V I$ : Ventilation Index $\left(\mathrm{L} \mathrm{min}^{-1}\right)$

$\dot{V}_{2 \max }:$ maximal $\mathrm{O}_{2}$ uptake $\left(\mathrm{ml} \mathrm{kg}^{-1} \min ^{-1}\right)$

\section{Introduction}

Work clothing is manufactured in various shapes and from a range of fabrics, according to its purpose. When creating clothing to be worn in conditions in which the body temperature is raised, designers must focus on minimising heat stress. This includes the selection of the fabric. To maintain thermal comfort of the body, it is important to maintain skin temperature and moisture within the comfort range, also during early stages of heat stress (Fanger, 1970; Gagge et al., 1967).

Air exchange between a clothing microclimate and an external environment has a significant effect on the wearer's evaporative and dry heat loss (Havenith et al., 1990; Bouskill et al., 2002). If exercise causes sweating, it is important to facilitate moisture 
diffusion through garments in order to keep the wearer comfortable. It is established that an increase in air exchange through the fabric, and through a garment's apertures, increases evaporative heat loss. Previous research has quantified the increase in clothing ventilation resulting from increases in fabric air permeability, and has examined the influence of apertures on clothing ventilation using work suits with identical design but different permeability (Ueda and Havenith, 2004). Based on these studies, an evaluation method was proposed, that uses a calculation of required ventilation: the ideal amount of ventilation by which all sweat produced could be removed from the skin to the outside of the clothes (Havenith et al., 2003), hence keeping skin moisture low and maintaining comfort.

The steady rate of sweating differs from one region of the body to another, and there are also regional differences in the degree of increase in sweat rate caused by increasing exercise intensity (Inoue et al., 1991; Inoue et al., 1995; Kondo et al., 1998). Determination of required clothing ventilation and comparison to actual ventilation requires knowledge about regional sweating characteristics and measurement of local ventilation rates. Use of this knowledge would allow better accuracy in evaluating clothing, and would allow collection of useful data for designing clothes with efficient diffusivity.

The purpose of this study was to explore the effect of clothing ventilation in three body regions on humidity in the local clothing microclimates of several work shirts immediately after the onset of sweating during light exercise. For this purpose, firstly local clothing microclimate ventilation in three body regions was measured, and secondly separate wear trials were performed to determine sweat production and humidity in the corresponding clothing microclimates, in the same conditions as the measurement of ventilation, during light exercise. 


\section{Method}

\section{Clothing}

Five long-sleeved shirts were chosen from commercially available samples, representing shirts that are typically worn by consumers in environmental conditions similar to those in this experiment. The shirt patterns were identical, but they were made of five different knits of cotton; Table 1 shows the characteristics of fabrics used in this experiment. The two sets of the five shirts were prepared respectively for each subject (a new shirt was used for each test). Each of them was kept in $25^{\circ} \mathrm{C} 50 \%$ rh until the test after being washed and dried beforehand.

take in Table 1

\section{Clothing ventilation at the chest, back, and upper arm}

Clothing ventilation was determined by measuring the Ventilation Index (VI), a product of air exchange rate multiplied by microclimate volume:

Ventilation Index $\left(\mathrm{L} \cdot \min ^{-1}\right)=$ air exchange rate $\left(\min ^{-1}\right) \times$ microclimate volume $(\mathrm{L})$ First, each of five shirts was placed on a manikin, and the microclimate volume was estimated by measuring the circumference of the undressed and clothed manikin body; this was approximated using a cylinder model (Lotens and Havenith, 1991). Subsequently, air exchange rates between the clothing microclimate and ambient air were measured at the three body regions of chest, back, and upper arm in a climatic chamber with an air velocity of less than $0.3 \mathrm{~m} \mathrm{~s}^{-1}$ using a tracer gas technique (Birnbaum and Crockford 1978; Bouskill et al., 2002). For this purpose, the concentration of oxygen was reduced from a natural level to approximately $10 \%$, by flushing $100 \%$ nitrogen gas into the microclimate under the shirt using a distribution tube system fixed to the surface of the manikin. Nitrogen injection was performed very carefully to reduce concentrations in the three regions at the same rate and to 
the same level.

Gas concentrations in three microclimate body regions were sampled separately using sampling tubes, also fixed to the surface of the manikin, and were sent to three corresponding oxygen analysers. After the nitrogen influx was halted, oxygen concentrations in the microclimate were monitored over an extended period of time while they returned to a natural environmental level (approximately 20.9\%) due to ventilation of microclimate air with ambient air. During this time, the oxygen levels increased from $11 \%$ to the natural level in the form of an exponential curve, and the resultant air exchange rates were calculated using the following equation:

$$
O_{2}(t)=A-B(0) \cdot e^{- \text {Rae.t }}
$$

where $\mathrm{O}_{2}(t)$ is the oxygen concentration (\%) at time t, $A$ is the asymptotic value of oxygen concentration $(20.9 \%), B(0)$ is a constant giving the difference between $A-\mathrm{O}_{2}(t)$ at $\mathrm{t}=$ 0 , and Rae is the air exchange rate calculated using least squares analyses. Measurements for each shirt were repeated seven times.

\section{$\underline{\text { Wear trials }}$}

To survey clothing microclimate humidity, wear trials were conducted using the five shirts in a neutral condition. Three healthy men served as subjects for the wear trials. The age of each three subjects was $36,22,32$ years; height 172, 179, $176 \mathrm{~cm}$; mass $72,8270 \mathrm{~kg}$; and surface area-to-mass ratio 247, 239, $258 \mathrm{~cm}^{2} \mathrm{~kg}^{-1}$, respectively. Each subject tested each shirt twice in two different workload conditions: 30 and $45 \% \dot{V}_{O_{2 m a x}}$, in balanced order. Therefore, each shirt was tested in six different sweat rate conditions. Each subject wore one of the shirts, underwear, socks, and long cotton trousers and he sat on a cycle ergometer for at least 15 minutes in a climatic chamber at a temperature of $25^{\circ} \mathrm{C}$, a relative humidity of $50 \%$, and with an air velocity of less than $0.3 \mathrm{~m} \mathrm{~s}^{-1}$ after the instruments were attached. The tests lasted until 
at least 15 minutes of sweating was observed. To maintain roughly equal microclimate volumes at the chest and back for the comparison of the different shirts on the same subject, subjects attempted to maintain an upright position. They were asked not to move the upper half of their bodies to reduce pumping effects, since an increase in pumping effect could change the airflow in and at the clothing surface.

Clothing microclimate temperature $\left(\operatorname{Tm}\left[{ }^{\circ} \mathrm{C}\right]\right)$ and relative humidity $(\mathrm{RHm}[\%])$ were continuously measured during exercise using temperature-humidity sensors (Shinei Kaisya THT-B) at the three regions of chest, back, and upper arm. Moisture concentration $\left[\mathrm{g} \mathrm{m}^{-3}\right]$ was calculated using Tm and RHm at each site (Goff, 1965).

Each minute during exercise, local skin temperature $\left(T s k\left[{ }^{\circ} \mathrm{C}\right]\right)$ was measured using skin thermistors at the chest, back, and upper arm, and rectal temperature $\left(\operatorname{Tre}\left[{ }^{\circ} \mathrm{C}\right]\right)$ was measured using a rectal probe. Local sweating rate $\left(m s w\left[\mathrm{~g} \mathrm{~min}^{-1} \mathrm{~m}^{-2}\right]\right)$ was measured at the chest, back, and upper arm using the ventilated capsule method. Dry nitrogen gas was supplied to the capsules (area $9 \mathrm{~cm}^{2}$ ) at a flow rate of $1 \mathrm{~L} \mathrm{~min}^{-1}$; humidity of nitrogen gas flowing out of the capsules was measured by capacitance hygrometry (Vaisala HMP133Y). Subjects were asked to declare their level of comfort (comfortable, slightly uncomfortable, uncomfortable, very uncomfortable), every 5 minutes immediately before exercise until it was completed.

All trials were performed during winter. Subjects were asked to refrain from other physical activity before the trials, and they did not ingest food or water from two hours before trials began until they were completed. All subjects considered themselves to be in good health, were not under a physician's care, and were not taking any medication. All subjects were given oral and written information about the procedures and possible risks involved in the study. Maximal $\mathrm{O}_{2}$ uptake $\left(\dot{\mathrm{V}}_{2 \max }\left[\mathrm{ml} \mathrm{kg}^{-1} \mathrm{~min}^{-1}\right]\right)$ was estimated for each subject while he exercised at a sub-maximal level; each subject pedalled on a cycle ergometer at a constant frequency of $50 \mathrm{rpm}$ for 5 minutes at four different exercise intensities. Heart rate (HR [bts 
$\left.\min ^{-1}\right]$ ) and $\mathrm{O}_{2}$ uptake were measured during the final minute of each exercise period. For each subject, $\dot{\mathrm{V}}_{\mathrm{O}_{\max }}$ was estimated by extrapolating the relationship between $\mathrm{HR}$ and $\mathrm{O}_{2}$ uptake to an estimated maximal HR for each subject.

\section{$\underline{\text { Data analysis and statistics }}$}

All data are expressed as mean $\pm \mathrm{SD}$. A one-way analysis of variance (ANOVA) was used to assess the statistical significance of differences in VI among five shirts and a one-way repeated-measures ANOVA was used to analyse differences in Tsk, Tm, $\mathrm{RHm}$ at the three body regions, Tre, and level of comfort among the five shirts. A two-way repeated-measures ANOVA was used to assess the statistical significance of differences in $m s w$ in the two within-subjects factors: the five shirts and the three body regions. To compare the Ventilation Index $(V I)$ in two typical samples, a paired-t test was used. All statistical analyses were performed using commercially available software (SPSS version 11.5; SPSS). A value of $p<$ 0.05 indicated statistical significance.

\section{Results}

\section{Clothing ventilation at chest, back, and upper arm}

Because the five shirts were made from an identical pattern, microclimate volumes of shirts showed no significant difference when worn on the same subject [trunk 10.3, upper arm $\left.2.0\left(\times 10^{3} \mathrm{~cm}^{3}\right)\right]$. Because the subjects maintained an upright position during exercise, the microclimate volume at the chest or back were assumed to be half of the total value for the trunk. Figure 1 shows the mean Ventilation Index $(V I)$ at the chest, back, and upper arm for each of the five shirts. Coefficients of variation $(\mathrm{CV}=\mathrm{SD} /$ mean value $(\%))$ ranged from 7-15\%. In each shirt, the chest had the greatest VI and the upper arm had the lowest VI. VI values at the chest and back differed significantly among the five shirts. Differences in $V I$ at 
the back were unclear compared to differences at the chest, and at the upper arm they were hardly discriminated.

take in Figure 1

\section{$\underline{\text { Wear trials }}$}

There were no significant differences in Tre, Tsk, or RHm among the shirts during the rest period; only chest $\mathrm{Tm}$ tended to show a lower temperature in sample 5 than in sample 4 (31.6 $\pm 0.5^{\circ} \mathrm{C}$ in sample 4 versus $30.7 \pm 0.6^{\circ} \mathrm{C}$ in sample $\left.5, \mathrm{p}=0.05\right)$. Under all clothing conditions, each subject voted that he was comfortable during the rest period. After exercise began, Tsk rose, and in all tests sweating was observed after some time had passed; sweating was observed at the chest, back, and upper arm at about the same time. The onset of sweating varied among trials and ranged from 3-10 minutes after exercise began $\left(30 \% \dot{\mathrm{V}}_{2 \max }: 7 \pm 2\right.$ $\left.\min ; 45 \% \dot{V}_{O_{2 \max }}: 5 \pm 2 \mathrm{~min}\right)$. As time passed, the sweat rate gradually increased. For all subjects, the level of comfort decreased after exercise began, and after the onset of sweating there was a difference in the voted level of comfort amonng the shirts. When voted levels of comfort are compared between two typical samples of clothing ventilation, samples 2 and 4 (similar thickness and weight, but different air permeability; Figure 2), the level of comfort for sample 4 (lower air permeability) appeared worse than that for sample 2 after the onset of sweating in five of the six trials. Figure 3 shows the levels of comfort 10 minutes after exercise began. Ten minutes after beginning the exercise, when all subjects first or second voted their level of comfort after the onset of sweating in each trial, there were significant differences $(\mathrm{p}<0.05)$ in levels of comfort. There were no significant differences in Tre, Tsk at the back or upper arm, or RHm at the chest, back, or upper arm at the time. Only chest Tsk had a tendency to be lower in sample 2 than in sample $4\left(34.8^{\circ} \mathrm{C}\right.$ in sample 2 versus $35.3^{\circ} \mathrm{C}$ in 
sample $4, \mathrm{p}=0.07)$

take in Figure 2 and Figure 3

Figure 4 shows mean values for average sweat rates in different body regions in all sessions over 10 minutes after the onset of sweating. There were large variations in deviation due to individual differences and differences in the absolute intensity of exercise. Sweat rates were significantly greater at the chest and back than at the upper arm. There were no significant differences in sweat rate among clothing conditions and the clothing condition-body region interaction. After investigating average values over the 10 minutes after the onset of sweating, there were no significant differences among clothing conditions in Tre, Tsk, Tm, and RHm.

take in Figure 4

To help clarify the interaction between sweat production, local ventilation, and resultant microclimate humidity, Figure 5 shows the relationship between the ratio of average moisture concentration in the clothing microclimate over the average sweat rate over 10 minutes after the onset of sweating, and the ventilation index. There was a clear relationship between these two variables at the chest and back. Sample 2, with a high ventilation index, demonstrated a lower ratio at the chest and back. On the other hand, sample 4, with an equal thickness and weight, but a lower air permeability fabric and a lower ventilation index, demonstrated a higher ratio. 


\section{Discussion}

The goal of this study was to explore the influence of clothing ventilation at the chest, back, and upper arm on humidity of clothing microclimates immediately after the onset of sweating when five permeable cotton shirts were worn during light exercise. This study was based on the hypothesis that increasing the amount of clothing ventilation would facilitate transport of produced sweat to the outside of clothes and hence, that clothing ventilation is an important factor during the initial stages of sweating to keep the wearer comfortable while working.

During the measurement of ventilation, when permeable shirts were tested using a manikin under still air conditions, clothing ventilation was better at the trunk than at the upper arm. This demonstrates that clothing ventilation from a microclimate to the environment differs among regions of the body. Air exchange through fabric is a complicated process affected by thermal ascending currents, air currents due to respiratory movement and/or body motion, a curved or waved fabric surface, a state of draping and other fabric properties. Clothing microclimate volumes directly affect clothing ventilation, and the thickness of air layers influence air currents in clothing microclimates. It is probable that these factors cause regional differences in clothing ventilation.

Air penetrating through fabric has an obvious effect on clothing ventilation, but though some indication of an air permeability effect was present (sample 2 vs 4 ) there was no clear correlation between fabric air resistance and clothing ventilation over all five garments together. Air resistance (R), as an index of air permeability, is measured with flattened fabric samples using a substantial fixed airflow rate through the fabric $(\mathrm{R}=\Delta \mathrm{P} / \mathrm{V}$, where $\Delta \mathrm{P}$ is the difference in pressure measured on both sides of a fabric, and $\mathrm{V}=0.04 \mathrm{~m}^{3} \mathrm{~m}^{-2} \mathrm{sec}^{-1}$ ). Under normal wearing conditions, the expected airflow rate through fabric is much lower; this may lead to differences in air resistance and ventilation index results. Factors such as fabric 
thickness, density, cover-factor, and surface characteristics may have different effects depending on test conditions. During actual wear, ventilation may also occur due to interactions among body regions; this cannot be observed during air permeability measurements. Investigation of clothing ventilation at various body regions will therefore lead to a more realistic evaluation of clothing than the simple examination of a fabric's air permeability.

Five cotton shirts of identical design were used in this experiment. Although they had different properties, there was no observed effect on the subjects' thermoregulatory responses before exercise began. Only the mesh structure of sample 5 resulted in a slightly lower chest Tm at rest, and this was only relative to sample 4 . This difference, however, did not have a large effect during exercise, as seen by the similar $\mathrm{Tm}$ for all samples. Given the low level of heat stress, the absence of a thermoregulatory effect is not surprising. However, all subjects reported reduced comfort in shirts with a lower VI compared to the shirts with a higher VI, comfort being a more sensitive parameter than the physiological responses in these conditions. Differences in comfort level were evident within 10 minutes after the onset of sweating in most trials. Average Tre, Tsk, Tm, and RHm values over the 10 minutes after the onset of sweating did not differ significantly among clothing conditions, so it is not possible to directly attribute observed differences in comfort levels to these parameters of thermoregulation. There was also no significant difference in average sweat rates over this period among the shirts, but there appeared to be a greater moisture concentration ratio in the clothing microclimate to sweat rate in shirts with a lower VI than in shirts with a higher VI. The difference in skin wettedness was probably considered to be the major cause of the differences in comfort levels over $10 \mathrm{~min}$ after the onset of sweating (Berglund et al., 1985). There appears to be a clear correlation between this ratio and VI, though it seems to vary among areas of the body. An increase in clothing ventilation may generally thin the diffusion zone 
and therefore improve evaporation efficiency. It is probable that the higher the ratio, the less the evaporative efficiency on the local skin surface, and that an increasing skin moisture concomitant with a lower evaporative efficiency reduces the level of comfort. This is confirmed when sample 2 is compared to sample 4 (equal thickness and weight, but different air permeability and VI). Figure 5 shows clear differences, which are reflected in the levels of comfort shown in Figures 3.

This experiment indicates that an increase in clothing ventilation is effective in keeping a wearer comfortable soon after the onset of sweating by preventing an increase in skin moisture concentration. The experiment also indicates that in order to design work wear or evaluate its conformability, clothing ventilation should be measured in different body regions in response to sweat rates in corresponding regions.

\section{Acknowledgements}

We thank our subjects for their cooperation. This work was supported in part by a Grant-in-Aid for Scientific Research from the Ministry of Education, Culture, Sport, Science and Technology of Japan (grant No.16500498).

\section{References}

1. Fanger, P. O. (1970) Thermal Comfort McGraw-Hill, N. Y.

2. Gagge A. P., Stolwijk J. A. J. and Hasrdy J. D. (1967) "Comfort and thermal sensations and associated physiological responses at various ambient temperatures", Environmental Research Vol. 1, pp. 1-20.

3. Havenith G., Heus R. and Lotens W.A. (1990) "Clothing ventilation, vapour resistance and permeability index: changes due to posture, movement and wind", Ergonomics Vol. 33, pp. $67-84$. 
4. Bouskill L.M., Havenith G., Kuklane K. Parsons K.C. and Withey W.R. (2002) "Relationship between clothing ventilation and thermal insulation", AIHA Journal Vol. 63, pp. 262-268.

5. Ueda H. and Havenith G. (2004) "The effect of fabric air permeability on clothing ventilation", in Tochihara Y. and Ohnaka T. (Ed), Environmental Ergonomics, Elsevier, UK, pp. 343-346.

6. Havenith G., Ueda H., Sari H. and Inoue Y. (2003) "Required clothing ventilation for different body regions in relation to local sweat rates", in Rossi R. (Ed), $2^{\text {nd }}$ European Conference on Protective Clothing, Montreux, Switzerland

7. Inoue Y., Nakao M., Araki T. and Murakami H. (1991) "Regional differences in the sweat responses of older and younger men", J. Appl. Physiol. Vol. 71, pp. 2453-2459.

8. Inoue Y., Nakao M., Okudaira S., Ueda H. and Araki T. (1995) "Seasonal variation in sweating responses of older and younger men", Eur. J. Appl. Physiol. Vol. 70, pp. 6-12.

9. Kondo N., Takano S., Aoki K., Shibasaki M., Tominaga H. and Inoue Y. (1998) "Regional differences in the effect of exercise intensity on thermoregulatory sweating and cataneous vasodilation", Acta Physiol. Scand. Vol. 164, pp. 71-78.

10. Lotens W.A. and Havenith G. (1991) "Calculation of clothing insulation and vapour resistance", Ergonomics Vol. 34, pp. 233-254.

11. Birnbaum R.R. and Crockford G.W. (1978) "Measurement of clothing ventilation index", Appl. Ergonomics Vol. 9, pp. 197-200.

12. Goff J. A.(1965) "Saturation Pressure of water on the new Kelvin", In Wexler A. (Ed), Humidity and moisture : measurement and control in science and industry, Reinhold Publishing, NY, pp. 289-292.

13. Berglund L.G., Gagge A.P., Cunningham D.J. and Oohori T (1985) "Vapor Resistence of Clothing, Local Skin Wettedness and Discomfort" ASHRAE Transaction Vol.91, pp. 3-12 


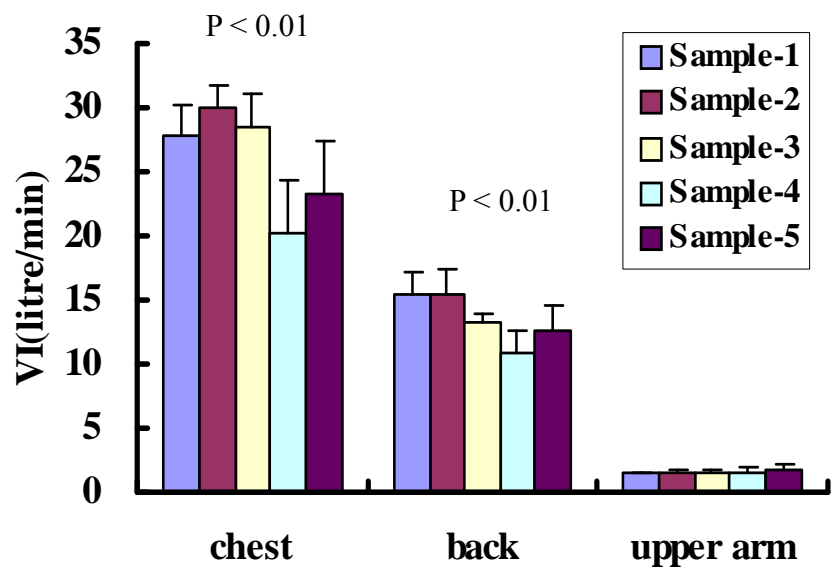

Fig. 1 Ventilation Index at the chest, back and upper arm. The $p$ value is for the effect of clothing conditions. 

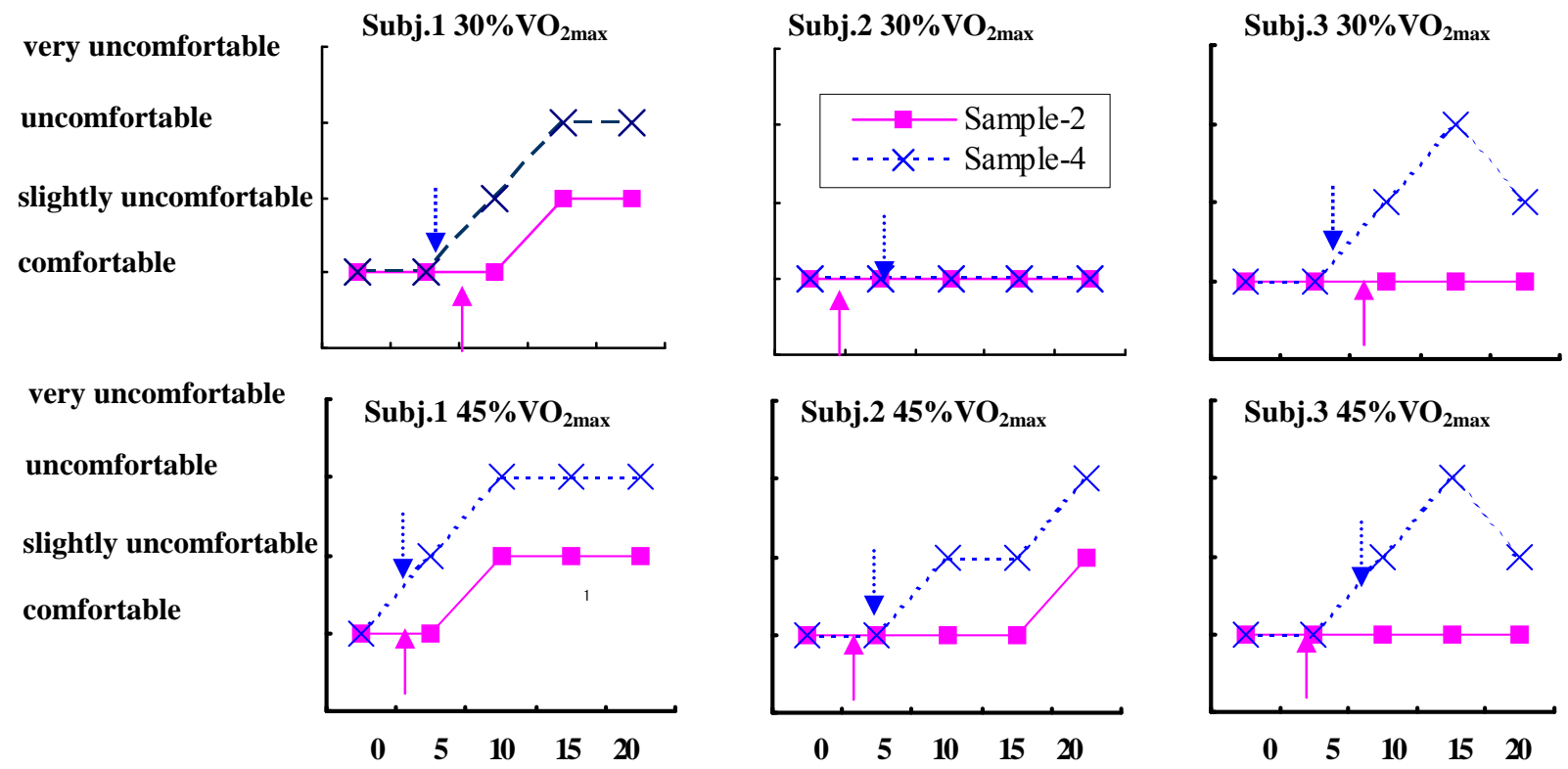

Fig. 2 Comfort sensations in Subj.1, 2 and 3 wearing sample 2 and 4 during the exercise. Arrows ( $\downarrow$ and $\uparrow$ ) indicate the onset of sweating. 


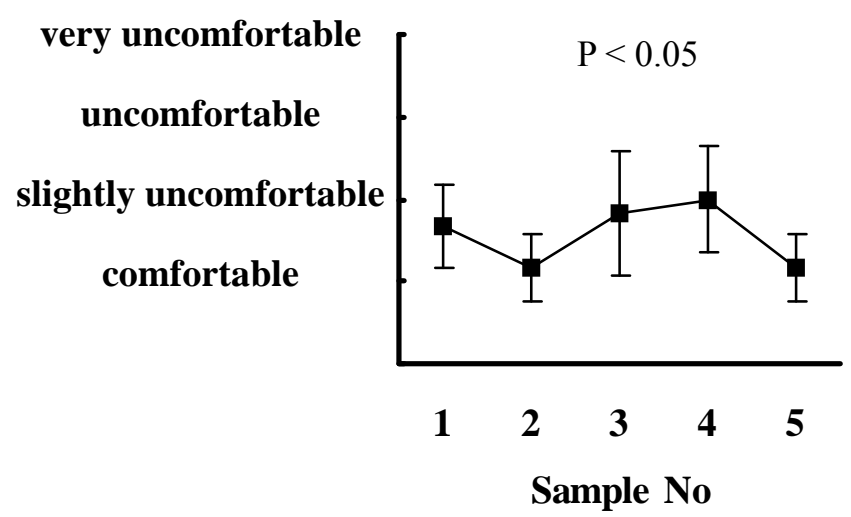

Fig. 3 Comfort sensations at $10 \mathrm{~min}$ after starting the exercise. The $p$ value is for the effect of clothing conditions. 


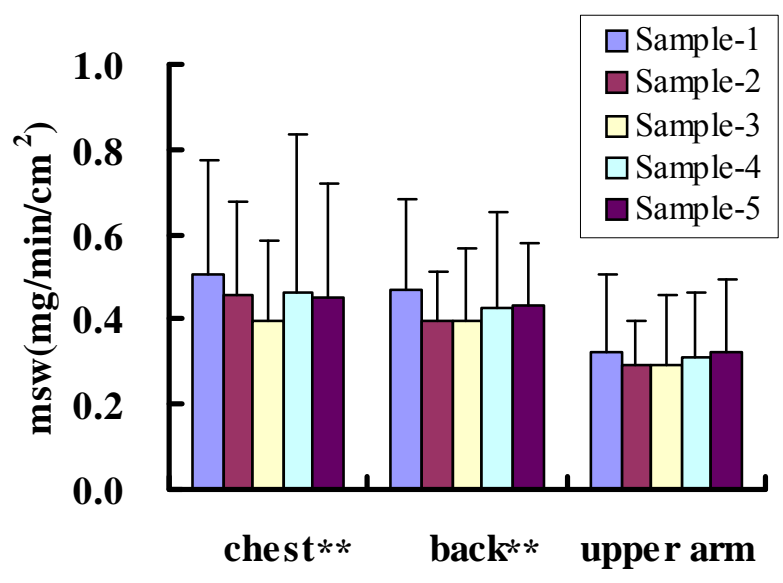

Fig. 4 Average sweat rate at chest, back and upper arm over 10 min after the onset of sweating. ${ }^{* *} \mathrm{P}<0.01$ from upper arm value. The $\mathrm{p}$ value is for the body regional effect. 


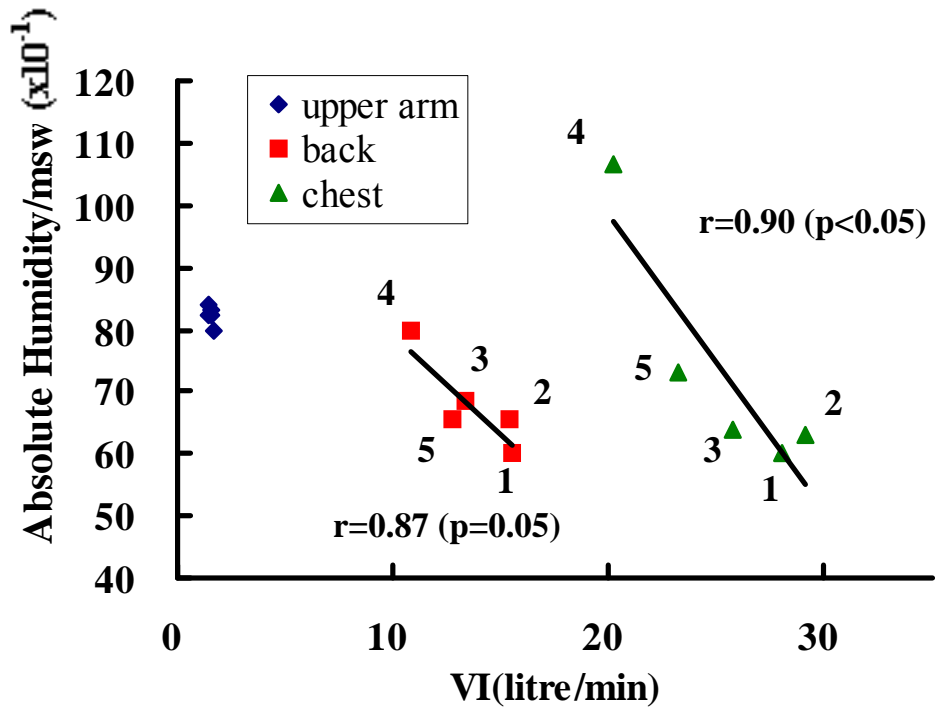

Fig. 5 Relationship between the ratio of average moisture concentration $\left[\mathrm{g} \mathrm{m}^{-3}\right]$ to average sweat rate $\left[\mathrm{g} \mathrm{min}^{-2}\right]$ and Ventilation Index $(V I)$ over 10 min after the onset of sweating. The numbers represent the samples. 
Table 1 Description of five shirts

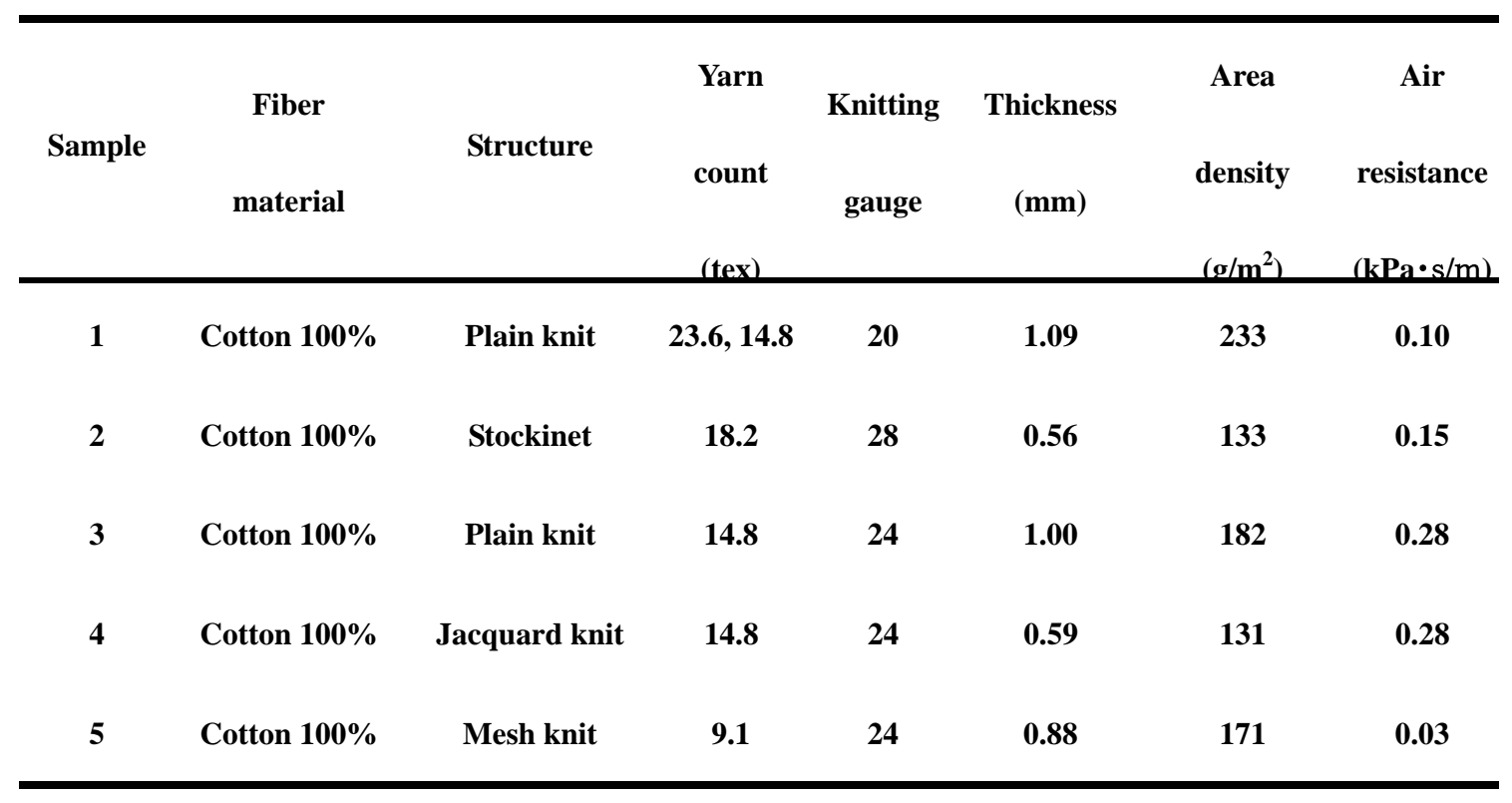

